\title{
ACTH after 15 min distinguishes between Cushing's disease and ectopic Cushing's syndrome: a proposal for a short and simple CRH test
}

\section{Katrin Ritzel, Felix Beuschlein, Christina Berr, Andrea Osswald, Nicole Reisch, Martin Bidlingmaier, Harald Schneider, Jürgen Honegger ${ }^{1}$, Lucas L. Geyer ${ }^{2}$, Jochen Schopohl and Martin Reincke}

Medizinische Klinik und Poliklinik IV, Klinikum der Universität München, Ziemssenstraße 1, D-80336 Munich, Germany, ${ }^{1}$ Department of Neurosurgery, University of Tuebingen, Tuebingen, Germany and ${ }^{2}$ Institut für klinische Radiologie, Klinikum der Ludwig-Maximilians-Universität München, Munich, Germany
Correspondence should be addressed to M Reincke Email Martin.Reincke@med. uni-muenchen.de

\begin{abstract}
Objective: The aim of the present study was to validate criteria of corticotropin-releasing hormone (CRH) stimulation and $8 \mathrm{mg}$ dexamethasone suppression (high-dose dexamethasone suppression, HDDS) to distinguish the etiology of ACTH-dependent Cushing's syndrome.
\end{abstract}

Subjects and methods: We retrospectively analyzed cortisol and ACTH after the injection of $100 \mu \mathrm{g}$ human CRH in confirmed Cushing's disease (CD, $n=78)$ and confirmed ectopic Cushing's syndrome (ECS, $n=18)$. Cortisol and ACTH increase (in percentage above basal $\left(\%_{\mathrm{B}}\right)$ ) at each time point, maximal increase $\left(\Delta \max \%_{\mathrm{B}}\right)$, and area under the curve $\left(A U C \%_{\mathrm{B}}\right)$ were analyzed using receiver operator characteristics (ROC) curve analyses. Cortisol suppression ( $\left.\%_{B}\right)$ after 8 mg of dexamethasone was evaluated as a supplementary criterion.

Results: An increase in ACTH of $\geq 43 \%_{\mathrm{B}}$ at $15 \mathrm{~min}$ after $\mathrm{CRH}$ was the strongest predictor of CD, with a positive likelihood ratio of 14.0 , a sensitivity of $83 \%$, a specificity of $94 \%$, a positive predictive value of $98 \%$ and a negative predictive value of $58 \%$. All of the other criteria of stimulated ACTH and cortisol levels were not superior in predicting CD in response to CRH injection. The addition of cortisol suppression by dexamethasone did not increase the discriminatory power. However, the combination of a positive ACTH response at $15 \mathrm{~min}$ and a positive HDDS test excluded ECS in all cases. Conclusion: The present findings support the use of plasma ACTH levels $15 \mathrm{~min}$ after the injection of human CRH as a response criterion for distinguishing between CD and ECS. The addition of the HDDS test is helpful for excluding ECS when both tests are positive.

\section{Introduction}

Adrenocorticotropin (ACTH)-dependent cortisol excess accounts for more than $80 \%$ of all cases of endogenous Cushing's syndrome (CS) (1). Distinction between pituitary and ectopic ACTH production is crucial for further treatment decisions. Because imaging can be unsatisfactory, or even misleading, in the differential diagnosis of ACTH-dependent Cushing's syndrome, a
(C) 2015 European Society of Endocrinology Printed in Great Britain precise biochemical diagnosis is mandatory. Bilateral inferior petrosal sinus sampling (IPSS), the gold standard test, is invasive and requires technical experience. Additionally, although a positive result predicts Cushing's disease (CD) with a positive predictive value (PPV) of about $99 \%$, the negative predictive value (NPV) is only about 20\% (2). 
The corticotropin-releasing hormone $(\mathrm{CRH})$ test is comparatively simple and therefore widely used for the evaluation of ACTH-dependent Cushing's syndrome. The rationale behind the $\mathrm{CRH}$ test is that corticotroph adenomas usually exhibit a hyper-responsiveness to $\mathrm{CRH}$, whereas the majority of ectopic ACTH-producing tumors do not respond to CRH. However, clinical experience and former research have demonstrated that a proportion of pituitary and ectopic tumors do not follow this functional pattern, which thus limits the reliability of the test (1). Ovine CRH was identified in 1981 and has since been utilized in a large number of studies. Human $\mathrm{CRH}$, which is supposed to be less immunogenic, is primarily used in Europe. Human CRH has a shorter circulation half-life that seems to provoke a less pronounced and shorter ACTH response as compared to ovine CRH. Evoked increases in cortisol levels are not different because the adrenal cortex is maximally stimulated by endogenous ACTH in both forms of CRH $(3,4)$.

Although there is a body of literature that has examined the diagnostic accuracy of the CRH test alone or in combination with the high-dose dexamethasone suppression (HDDS) test, the results of these analyses are equivocal $(5,6)$. There is substantial disagreement about which response parameters and cutoff levels are most suitable for differential diagnosis of CS. As a result, protocols of the CRH test vary considerably at different centers with respect to time points and duration of sampling, the injection of human or ovine $\mathrm{CRH}$, the dosage of $\mathrm{CRH}$, and the criteria for interpreting the CRH test.

The aim of the present study was to reevaluate the criteria for ACTH and cortisol responses to $100 \mu \mathrm{g}$ human CRH in a large series of patients with ACTH-dependent Cushing's syndrome. Furthermore, we evaluated the additional value of the HDDS test in order to distinguish the etiology of ACTH-dependent CS.

\section{Subjects and methods}

We retrospectively analyzed serum cortisol and plasma ACTH concentrations of $\mathrm{CRH}$ tests in patients with confirmed CD and confirmed ECS. A cohort of 87 of the 152 (57\%) patients treated at our institution for ACTHdependent CS from 1994 until 2014 was included in the analyses. The remaining patients were excluded because no CRH test was performed at our institution $(n=56)$, because ACTH-dependent CS was of undefined origin, or because the patient was lost to follow-up $(n=9)$. The pituitary origin of ACTH secretion was established by biochemical remission following transsphenoidal surgery (TSS), histopathology, and/or temporary adrenal insufficiency after surgery. Ectopic ACTH production was confirmed by histopathology and/or cure after surgery. In nine of the patients with $\mathrm{CD}$, a second $\mathrm{CRH}$ test was performed because of recurrent disease. Altogether 96 $\mathrm{CRH}$ tests were analyzed. In $81 \%$ of the tests, the final diagnosis was $\operatorname{CD}(n=78)$, and in $19 \%$ of the tests the patients were diagnosed with ECS $(n=18)$. Additionally, in 74 of 96 cases (77\%), data from overnight $8 \mathrm{mg}$ dexamethasone suppression testing were available.

The CRH test was performed in the morning after an overnight fast. Blood samples for serum cortisol and plasma ACTH were drawn at -15 and 0 min before and at $15,30,45,60,90$, and $120 \mathrm{~min}$ after the injection of $100 \mu \mathrm{g}$ human CRH (Ferring Arzneimittel GmbH).

The following criteria for differentiating between CD and ECS were tested: i) the percentage increases above basal $\left(\%_{\mathrm{B}}\right)$ for ACTH and cortisol at each time point between 15 and $120 \mathrm{~min}$; ii) the sum of ACTH and cortisol increases $\left(\%_{\mathrm{B}}\right)$ at various time points; iii) the maximal increase in ACTH and cortisol above basal $\left(\Delta \max \%_{\mathrm{B}}\right)$ across the investigation interval; iv) the area under the curve of ACTH and cortisol responses (AUC \% $\%_{\mathrm{B}}$ ) as calculated by trapezoidal approximation; and $\mathrm{v}$ ) the mean cortisol increase 15 and $30 \mathrm{~min}$ after $\mathrm{CRH}$, which was a criterion proposed in a previous study (7).

In addition to the CRH test, a subgroup of the patients underwent HDDS testing, with $8 \mathrm{mg}$ of dexamethasone (Jenapharm GmbH, Jena, Germany) being administered at $2300 \mathrm{~h}$ and a cortisol measurement at $0800 \mathrm{~h}$ the next morning. The suppression of cortisol secretion as a percentage of the basal cortisol level measured on a different day between 0800 and $1000 \mathrm{~h}$ was calculated. Additionally, the sum of ACTH secretion following CRH stimulation and cortisol suppression following dexamethasone administration was examined.

Data are presented as means and s.E.M. The optimal cutoff level and associated sensitivity and specificity were evaluated by receiver operator characteristics (ROC) curve analyses based on the highest positive likelihood ratio (+LR) using GraphPad Prism 5 software (GraphPad, San Diego, CA, USA). PPV and NPV were calculated with Bayes's formula. Post-test probability was calculated using the following formulas: post-test probability $=$ post-test odds $/(1+$ post-test odds $) ;$ post-test odds $=$ pre-test odds $\times$ LR, pre-test odds $=$ pre-test probability $/(1-$ pre-test probability); pre-test probability $=$ prevalence. Finally, we estimated the number of patients that were either correctly diagnosed or misdiagnosed when the strongest 
criteria of the CRH test and the dexamethasone test were applied.

ACTH and cortisol were measured using an automated chemiluminescence assay (Liaison, Diasorin, Italy) as per the manufacturer's instructions. In our hands, for ACTH, within-assay coefficient of variations ( $\mathrm{CV}$ values) were $6.7 \%$ at $5.8 \mathrm{pg} / \mathrm{ml}$ and $1.2 \%$ at $355.4 \mathrm{pg} / \mathrm{ml}$, and betweenassay $\mathrm{CV}$ values were $12.7 \%$ at $13.9 \mathrm{pg} / \mathrm{ml}$ and $9.4 \%$ at $354.7 \mathrm{pg} / \mathrm{ml}$. For cortisol, within-assay CV values were $2.2 \%$ at $0.5 \mu \mathrm{g} / \mathrm{dl}$ and $3.9 \%$ at $4.5 \mu \mathrm{g} / \mathrm{dl}$, and between-assay $\mathrm{CV}$ values were $9.8 \%$ at $0.2 \mu \mathrm{g} / \mathrm{dl}$ and $9.6 \%$ at $4.4 \mu \mathrm{g} / \mathrm{dl}$.

Data for the present analysis were obtained from the Munich center of the German Cushing Registry. All of the patients included in the present analysis gave written informed consent for the use of their data. The German Cushing Registry was approved by the ethics committee of the University Hospital of Munich and the ethics committees of the participating centers.

\section{Results}

The patient's characteristics are reported in Table 1. Patients with confirmed ECS suffered from pulmonary carcinoid in 14 cases, from small-cell lung cancer in three cases, and from an ACTH-producing paraganglioma in one case.

In patients with $\mathrm{CD}, \mathrm{ACTH}$ concentrations significantly increased from $71( \pm 8)$ to a maximum of $191( \pm 20) \mathrm{pg} / \mathrm{ml}(P<0.001)$ at $15 \mathrm{~min}$ and reached basal values $90 \mathrm{~min}$ after $\mathrm{CRH}$ injection. In patients with ECS, there was no significant rise in ACTH values (Fig. 1A). Cortisol concentration after CRH increased from $23( \pm 1)$ to a maximum of $36( \pm 4) \mu \mathrm{g} / \mathrm{dl}$ after $45 \mathrm{~min}(P<0.001)$ in patients with CD. Again, there was no significant increase in serum cortisol from the basal value $(31 \pm 5 \mu \mathrm{g})$ after $\mathrm{CRH}$ in patients with ECS (Fig. 1B). There was considerable overlap of ACTH and cortisol responses between patients with pituitary and ectopic Cushing's syndrome (Fig. 2). The results of the ROC curve analysis of different test variables along with the corresponding cutoff level and statistic characteristics are provided in Table 2.
An ACTH increase of $\geq 43 \%_{\mathrm{B}}$ at $15 \mathrm{~min}$ after $\mathrm{CRH}$ administration had the highest $+\mathrm{LR}$, sensitivity, and NPV along with high specificity and high PPV. ACTH values obtained after $15 \mathrm{~min}$ after CRH injection had lower sensitivity, and those obtained after $60 \mathrm{~min}$ also had lower specificity as compared to the early increase. Incremental ACTH in percentage above basal over 120 min had lower + LR, sensitivity, and NPV as compared to ACTH increase after $15 \mathrm{~min}$ as well. Maximal ACTH increase over $120 \mathrm{~min}$ had less favorable characteristics than ACTH measurement after 15 min did.

For cortisol, the most favorable ROC curve statistic was achieved after $30 \mathrm{~min}$, with a cutoff of $\geq 32 \%_{\mathrm{B}}$ increase. All of the other time points were associated with lower sensitivity and a lower LR. Likewise, incremental cortisol over $120 \mathrm{~min}$ and maximal cortisol rise were less sensitive for discriminating between CD and ECS.

The combination of cortisol and ACTH increase in percentage above basal at various time points showed lower sensitivity than ACTH increase at 15 min alone, along with the same specificity and slightly lower LR.

In clinical practice, commonly used cutoff values of the CRH test are a $30 \%$ rise in cortisol and a 50\% rise in ACTH after human $\mathrm{CRH}$ injection. Applying these criteria, ROC curve analysis showed a sensitivity of $78 \%$, a specificity of $78 \%$, and an LR of 3.5 for cortisol and a sensitivity of $83 \%$, a specificity of $89 \%$ and an LR of 7.5 for ACTH.

When ROC analysis was performed using mean cortisol increase after 15 and $30 \mathrm{~min}$, as previously published (7), a maximal LR of 10.5 at a cutoff level of $24 \%$ with a sensitivity of $59 \%$ and a specificity of $94 \%$ was achieved. A cutoff value of $14 \%$, as proposed by Newell-Price et al., had higher sensitivity (73\%) at the cost of lower specificity (78\%), which resulted in a low LR of 3.3. Mean ACTH increase at 15 and $30 \mathrm{~min}$ after $\mathrm{CRH}$ injection resulted in a maximal LR of 13.1 at a cutoff level of $77 \%$, with $73 \%$ sensitivity and $94 \%$ specificity. When a previously hypothesized cutoff level of $9 \%$ was applied (8), specificity dropped to $50 \%$.

Table 1 Patient's characteristics.

\begin{tabular}{|c|c|c|c|c|c|c|c|c|c|c|c|}
\hline & $\boldsymbol{n}(\%)$ & $\begin{array}{c}\text { Age } \\
\text { (years) }\end{array}$ & $\begin{array}{c}\text { Females, } \\
n(\%)\end{array}$ & TSS, n (\%) & $\begin{array}{c}\text { BADx, } \\
\text { n }(\%)\end{array}$ & $\begin{array}{l}\mathbf{A C T H}_{\mathbf{B}} \\
(\mathrm{pg} / \mathrm{ml})\end{array}$ & $\begin{array}{c}\text { Cortisol }_{\mathbf{B}} \\
(\mu \mathrm{g} / \mathrm{dl})\end{array}$ & $\begin{array}{c}\text { HDDS, } \\
\text { n }(\%)\end{array}$ & $\begin{array}{c}\downarrow \text { Cortisol } \\
\left(\%_{\mathrm{B}}\right)\end{array}$ & $\begin{array}{l}\text { IPSS, } \\
\text { n (\%) }\end{array}$ & $\begin{array}{l}\text { Positive } \\
\text { IPSS (\%) }\end{array}$ \\
\hline$C D$ & $78(81)$ & $43 \pm 2$ & $61(78)$ & 78 (100) & $11(14)$ & $71 \pm 8$ & $23 \pm 1$ & $64(82)$ & $71 \pm 5$ & $23(30)$ & 19 (83) \\
\hline ECS & 18 (19) & $51 \pm 4$ & $11(61)$ & 2 (11) & 7 (39) & $106 \pm 19$ & $31 \pm 5$ & $14(78)$ & $31 \pm 7$ & $5(28)$ & $0(0)$ \\
\hline
\end{tabular}

CD, Cushing's disease; ECS, ectopic Cushing's syndrome; TSS, transsphenoidal surgery; BADx, bilateral adrenalectomy; HDDS: high dose (8 mg) dexamethasone suppression; $\downarrow$ Cortisol $\%_{\mathrm{B}}$, percentage suppression of cortisol after HDDS above basal; IPSS, inferior petrosal sinus sampling; Positive IPSS, central to peripheral gradient after $\mathrm{CRH}>3$. 
A $\ominus$ ECS - CD

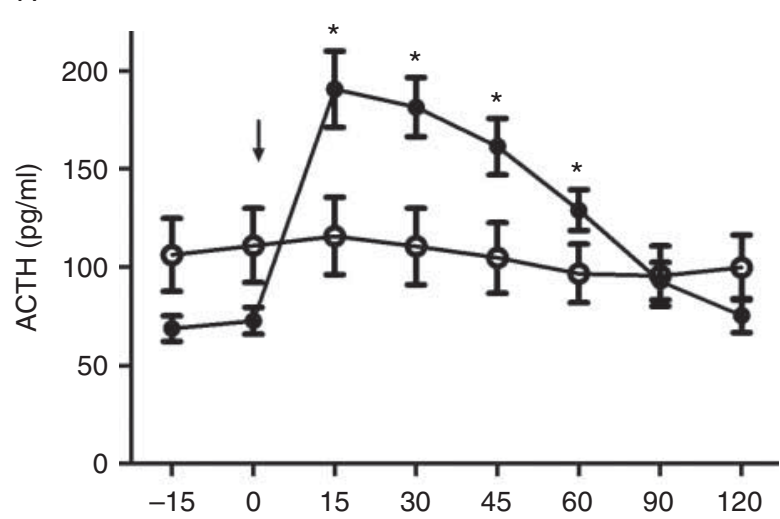

B



Figure 1

Plasma ACTH (A) and serum cortisol (B) excursion in patients with Cushing's disease (CD, closed symbols) and ectopic Cushing's syndrome (ECS, open symbols) after the injection of $100 \mu \mathrm{g}$ human corticotropin-releasing hormone ( $\mathrm{CRH}$, downward arrow). Asterisks indicate statistical significant increase as compared to baseline concentration $(<0.001)$.

ROC curve analysis of the HDDS test showed the highest LR (8.9), with a cutoff value of $\geq 71 \%$ suppression of basal cortisol and a corresponding sensitivity of $64 \%$ and specificity of $93 \%$. The clinically recommended cutoff for $50 \%$ cortisol suppression had an LR of only 3.0, and even though sensitivity was strong (86\%), specificity reached only $71 \%$. The combination of both tests calculated the sum of cortisol suppression and ACTH increase at $15 \mathrm{~min}$ after CRH injection and had an LR of 11.0 , a cutoff value of $119 \%$, a sensitivity of $80 \%$, a specificity of $93 \%$, a PPV of $98 \%$, and an NPV of $53 \%$.

When the strongest criteria of the CRH test ( $>43 \%$ increase in ACTH 15 min after $\mathrm{CRH}$ injection) and the results of the HDDS test were concurrently applied $(n=74), 68 \%$ of the patients were correctly diagnosed as CD, and no patient with ECS was misdiagnosed
(PPV: 100\%, NPV: 43\%). Both tests were negative in only $2 \%$ of the patients with $\mathrm{CD}$, whereas $64 \%$ of the patients with ECS had negative results when both tests were applied together (Fig. 3).

The results of the ROC curve analysis separated for female and male patients (data not shown). The cortisol and ACTH excursions after CRH were not statistically different between female and male patients (data not shown). The results of the ROC curve analysis of the female cohort were similar to the results obtained from the entire cohort. An increase in ACTH after 15 min did not differ between the female cohort and the entire cohort. Values of post-test probability calculated directly from the female cohort did not differ much from the post-test probability of the entire cohort (data not shown). ROC curve characteristics of the male cohort differed from the female cohort as well as from the entire cohort.

\section{Discussion}

Although the CRH test for the differential diagnosis of ACTH-dependent CS has been evaluated in the past, the present analysis reveals some new aspects. The most interesting outcome is that ACTH increase after $15 \mathrm{~min}$ was the strongest predictor of CD and was superior to all of the additional parameters evaluated. The amplitude of fast ACTH rise after $15 \mathrm{~min}$ in patients with CD yielded the highest discriminatory power as compared to the flat curve of ACTH in patients with ECS (Figs 1 and 2). In addition, ACTH increase after $15 \mathrm{~min}$ was a stable criterion in the sex-specific analysis, with almost identical results for the female and for the total cohort. Results from ROC curve analysis of the male cohort did not allow firm conclusions to be drawn because of the low number of subjects in the male cohort ( $<20$ cases). ROC curve analysis is suggested to allow valid conclusions only with more than 90 observations.

The present analysis was performed with human CRH. Former kinetic analyses have demonstrated that in comparison to ovine $\mathrm{CRH}$, the human peptide has a faster metabolic clearance rate, which results in a less pronounced and shorter ACTH peak $(3,9)$. This might explain why in previous studies with ovine $\mathrm{CRH}$, later time points across the time series showed better diagnostic abilities as compared to ACTH increase after $15 \mathrm{~min}$ in the present series (10). Thus, the present results are specific for human and not ovine CRH tests.

A large European series examined $171 \mathrm{CRH}$ tests using human and ovine CRH (11) and reported a sensitivity of $85 \%$ and a specificity of $100 \%$ at a maximum increase in 


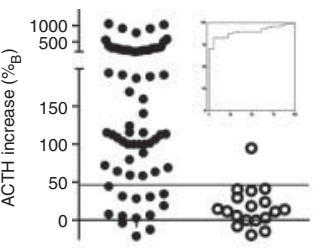

ACTH (15 min)
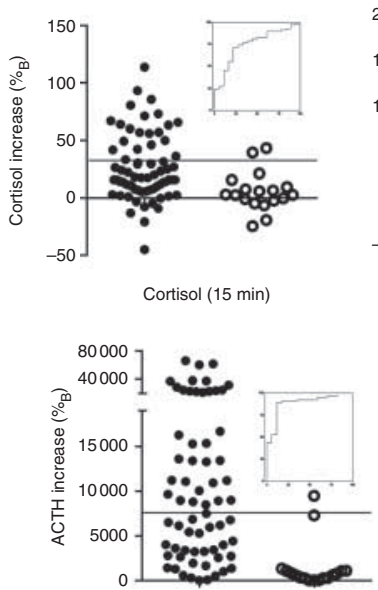

AUC ACTH

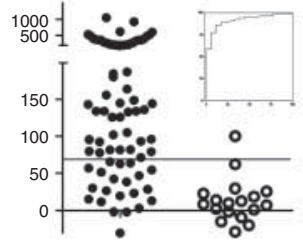

ACTH (30 min)

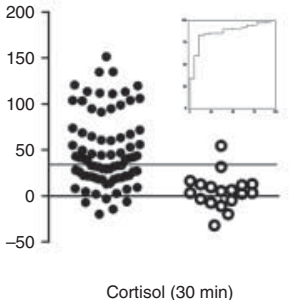

Cortisol (30 min)

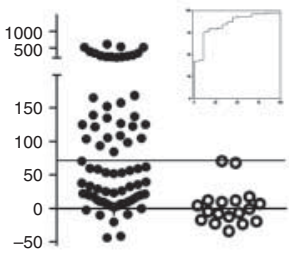

ACTH (60 min)

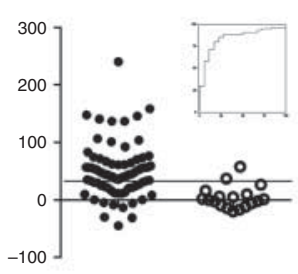

Cortisol (60 min)

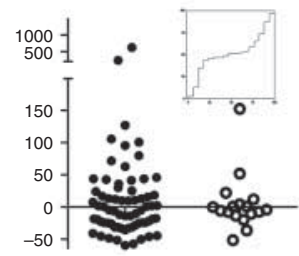

ACTH (120 min)

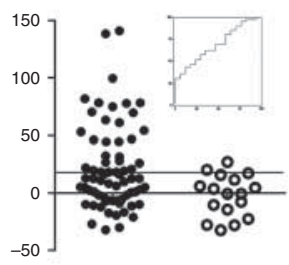

Cortisol (120 min)



ACTH (max)

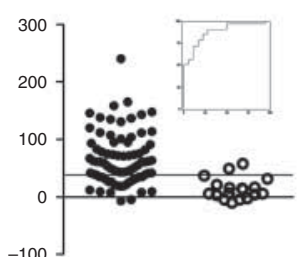

Cortisol (max)


CRH:ACTH $15 /$ HDDS

\section{Figure 2}

Distribution of different response variables of the corticotropinreleasing hormone ( $\mathrm{CRH}$ ) test and the high-dose dexamethasone suppression (HDDS) test in a series of 78 patients with Cushing's disease (CD, closed symbols) and 18 patients with

ACTH of $>50 \%$ after CRH. An increase in ACTH of $>50 \%_{\mathrm{B}}$ is also often used in clinical practice. We applied this criterion to the present series, and it resulted in similar sensitivity but lower specificity. In the present series, there were two patients with ECS who responded with a distinct rise in $\mathrm{ACTH}$ and cortisol to $\mathrm{CRH}\left(>90 \%_{\mathrm{B}}\right.$ and $>50 \%_{\mathrm{B}}$ respectively) despite a histology-proven ACTH-producing carcinoid. These patients had particularly low basal ACTH and cortisol levels, which possibly contributed to a diminished negative feedback inhibition that is otherwise believed to be one mechanism for negative CRH response in patients with ECS (12). Thus, mild or cyclic hypercortisolism could be a cause for false-positive ACTH response to $\mathrm{CRH}$ in ECS, and the timing of functional testing might impact the outcome.

In the present analysis, an ACTH increase at $15 \mathrm{~min}$ had a better discriminative power, with a higher number of correctly identified patients with ECS as compared to maximal ACTH increase after $\mathrm{CRH}$ injection. A possible explanation for this observation might be that a longer ectopic Cushing's syndrome (ECS, open symbols). The bar indicates the cutoff level obtained by ROC curve analysis based on the highest likelihood ratio. The ROC curve of each analysis is inserted in the right corner of the graph.

sampling period increases the likelihood of spontaneous bursts of ACTH secretion in ectopic tumors that resemble CRH-stimulated peaks in CD.

Newell-Price et al. (7) investigated a large series of human $\mathrm{CRH}$ tests and found a maximal ACTH response of $>105 \%$ above basal to have $100 \%$ specificity but a rather low sensitivity. Because of the low sensitivity, these authors postulated the superiority of cortisol as the best criterion for differentiating between CD and ECS. In contrast, the present data showed a sluggish and quantitatively small cortisol increase (Fig. 1) and less favorable results in ROC analysis as compared to ACTH (Table 2). The major methodological difference between their work and the present study is that we used ROC curve analysis based on the highest LR to define cutoff values. LRs express the clinical usefulness of a test by measuring the change in the certainty of diagnosis. An LR greater than 10 is considered to be a strong indicator that the test will predict the presence of the disease. In contrast, NewellPrice et al. estimated their cutoff levels at a preset 
Table 2 ROC curve characteristics of different test variables.

\begin{tabular}{|c|c|c|c|c|c|c|c|c|}
\hline Test variable & $\begin{array}{l}\text { Cutoff value } \\
(\%)\end{array}$ & ROC AUC (S.E.M.) & Positive LR & $\begin{array}{l}\text { Sensitivity } \\
(\%)\end{array}$ & $\begin{array}{l}\text { Specificity } \\
(\%)\end{array}$ & PPV (\%) & $\begin{array}{l}\text { NPV } \\
(\%)\end{array}$ & $\begin{array}{c}\text { Post-test } \\
\text { probability (\%) }\end{array}$ \\
\hline АСТН (15 min) & $\geq 43$ & $0.89(0.03)$ & 14.9 & 83 & 94 & 98 & 58 & 98 \\
\hline АСТH (30 min) & $\geq 62$ & $0.91(0.03)$ & 13.9 & 77 & 94 & 98 & 50 & 98 \\
\hline ACTH (45 min) & $\geq 51$ & $0.89(0.04)$ & 12.5 & 69 & 94 & 98 & 40 & 98 \\
\hline АСТH (60 min) & $\geq 69$ & $0.85(0.05)$ & 8.0 & 42 & 94 & 97 & 30 & 97 \\
\hline Cortisol (15 min) & $\geq 41$ & $0.75(0.06)$ & 4.9 & 28 & 94 & 95 & 24 & 95 \\
\hline Cortisol (30 min) & $\geq 32$ & $0.87(0.04)$ & 10.9 & 59 & 94 & 98 & 37 & 98 \\
\hline Cortisol (45 min) & $\geq \mathbf{5 0}$ & $0.85(0.05)$ & 8.4 & 46 & 94 & 97 & 31 & 97 \\
\hline $\begin{array}{l}\text { ACTH }(15 \mathrm{~min})+\text { Cortisol } \\
(30 \mathrm{~min})\end{array}$ & $\geq 110$ & $0.90(0.03)$ & 13.4 & 74 & 94 & 98 & 48 & 98 \\
\hline $\begin{array}{l}\text { ACTH }(30 \mathrm{~min})+\text { Cortisol } \\
(30 \mathrm{~min})\end{array}$ & $\geq 108$ & $0.90(0.03)$ & 12.8 & 71 & 94 & 98 & 45 & 98 \\
\hline$\Delta_{\max }$ ACTH (120 min) & $\geq 95$ & $0.90(0.04)$ & 12.9 & 71 & 94 & 98 & 46 & 98 \\
\hline$\Delta_{\max }$ Cortisol $(120 \mathrm{~min})$ & $\geq 49$ & $0.88(0.04)$ & 10.5 & 55 & 94 & 97 & 35 & 97 \\
\hline AUC ACTH $\left(\%_{B}\right)$ & $\geq 7375$ & $0.89(0.04)$ & 9.0 & 52 & 94 & 97 & 33 & 97 \\
\hline AUC Cortisol $\left(\%_{\mathrm{B}}\right)$ & $\geq 3040$ & $0.86(0.05)$ & 10.4 & 67 & 94 & 98 & 38 & 98 \\
\hline $\mathrm{HDDS}+\mathrm{ACTH}_{\mathrm{CRH}} 15 \mathrm{~min}$ & $\geq 119$ & $0.94(0.03)$ & 11.2 & 72 & 93 & 98 & 53 & 98 \\
\hline
\end{tabular}

AUC, area under the curve; + LR, positive likelihood ratio; PPV, positive predictive value; NPV, negative predictive value.

specificity of $100 \%$. We decided not to follow this approach, because we believe that $100 \%$ specificity is difficult to obtain with the CRH test. It has been well documented that a small number of patients with ECS show a clear cortisol and ACTH response to CRH, especially patients with carcinoids $(13,14,15,16,17,18$, 19). Presetting specificity to $100 \%$ will always lead to a pronounced reduction in sensitivity. Because the pretest probability of $\mathrm{CD}$ is more than four times higher than that of ECS, a significant reduction in sensitivity can cause a greater proportional increase in false-negative results.

In contrast to the results of the present analysis, several other reports have found serum cortisol to be a stronger predictor of CD than ACTH is $(8,20,21)$. Those earlier analyses reported a cortisol increase of $20 \%$ or even less as the most suitable cutoff. In the present series, a cutoff for cortisol of less than 20\% would indeed be associated with a higher sensitivity, but it would simultaneously result in a low specificity of less than $75 \%$, because more than one-quarter of the patients with ECS exhibited maximal cortisol excursions of more than $20 \%$ above basal. In general, using a threshold that is less than four times the intra-assay CV (5-8\%) is controversial, seeing as test results become more vulnerable to other effects than they do to the CRH stimulus. Therefore, we believe that the ACTH increment in response to CRH is a more robust criterion than a modest cortisol rise is.

In the present series, ROC curve analysis proved the HDDS test to be inferior to the CRH test in distinguishing $\mathrm{CD}$ from ECS. The combined analysis of the CRH and the HDDS test did not increase diagnostic precision in the
ROC analysis. These results are in accordance with previous data that showed that the HDDS test in combination with the CRH test was not superior to the CRH test alone $(13,19,22)$ or the CRH test in combination with the $48 \mathrm{~h}$ low-dose dexamethasone suppression test (16). Nevertheless we believe that the HDDS test can still have some impact in the differential diagnosis of

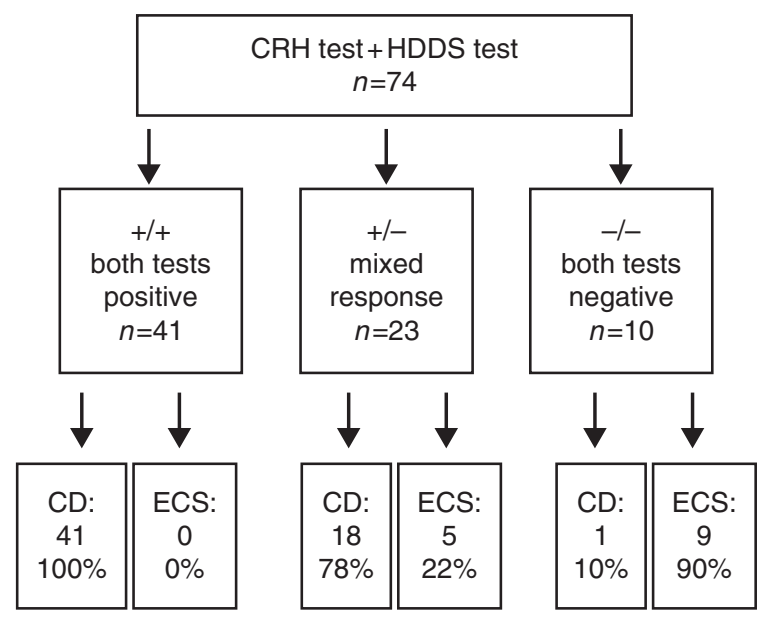

Figure 3

Combined test response to the corticotropin-releasing hormone (CRH) test (response criterion: ACTH rise of $>43 \%{ }_{\mathrm{B}} 15 \mathrm{~min}$ after the injection of $100 \mu \mathrm{g}$ human $\mathrm{CRH}$ ) and the high-dose dexamethasone suppression (HDDS) test (response criterion: cortisol suppression of $>50 \%{ }_{B}$ after $8 \mathrm{mg}$ of dexamethasone) in patients with Cushing's disease (CD) and patients with ectopic Cushing's syndrome (ECS). 
ACTH-dependent CS. We found that not one single patient with CD was misdiagnosed as having ECS when the combination of a positive $\mathrm{CRH}$ test and a positive HDDS test were present (PPV 100\%). Therefore, a positive $\mathrm{CRH}$ test with an ACTH of $>43 \%$ after $15 \mathrm{~min}$ and a positive HDDS test of more than 50\% cortisol substantiated the diagnosis of pituitary CS, which led to TSS without further biochemical tests. Still, 30\% of the patients with CD and 36\% of the patients with ECS had a mixed response. In these situations, the next logical step for differentiating CD from ECS would be IPSS. Imaging of the pituitary region is generally performed before IPSS. Pituitary MRI might reveal a larger pituitary tumor, which would indicate an ACTH-producing pituitary adenoma (11). On the other hand, in up to $50 \%$ of patients with proven CD, the MRI fails to detect the source of ACTH secretion, and more than $15 \%$ of the patients with ECS carry incidental pituitary tumors $(2,11,23)$. Thus, from a clinical point of view, imaging is required before IPSS, whereas from a scientific point of view, the diagnostic abilities of imaging are limited and are inferior to the discriminatory abilities of dynamic biochemical tests. IPSS has been suggested to be the most accurate test for differentiating CD from ECS (24). The predictive value of a positive IPSS with CRH stimulation is high. False-positive IPSS are either a result of ectopic CRH secretion or of the insufficient suppression of regular corticotropin feedback by only mild or periodic hypercortisolism. The rate of false-negative IPSS is, to some extent, influenced by the investigators' experience, and it ranges from 80 to $99 \%$ $(2,25,26)$. In cases of negative IPSS despite normal venous anatomy:draining, prolactin normalized IPS:P ratios might decrease the number of false-negative results (27). Because neither biochemical functional testing nor imaging and IPSS have 100\% sensitivity and specificity in the differential diagnosis of ACTH-dependent CS, only a differentiated combination of these tests can minimize the number of patients with uncertain diagnoses.

In summary, the present study has two main findings: i) an early ACTH increase after CRH stimulation identifies patients with CD; and ii) ECS is excluded when the CRH test plus the HDDS test are positive. However, like all previous series, the present work has important limitations. First, the present study was designed as retrospective analysis that is susceptible to selection bias, especially seeing as not all of the patients who underwent $\mathrm{CRH}$ testing were available for follow-up. Second, the overall number of patients included in the present analysis and, in particular, the number of patients with ECS was small, which limited the study power. If these results can be confirmed in larger prospective series and be implemented in clinical practice, the diagnostic work-up in patients with ACTH-dependent CS could be simplified and standardized, and this is urgently needed.

\section{Conclusion}

The present analysis supports the use of plasma ACTH increase $15 \mathrm{~min}$ after $\mathrm{CRH}$ injection as a powerful response criterion for distinguishing between CD and ECS. If these results can be confirmed in a larger prospective series, a single sample after a CRH injection could replace the timeconsuming sampling of time series. In addition, a positive $\mathrm{CRH}$ test using ACTH response after $15 \mathrm{~min}$ in combination with a positive HDDS test allowed excluding ECS in patients with ACTH-dependent CS in the present series.

\section{Declaration of interest}

$M$ Reincke has served on the advisory boards of Novartis and has received lecture fees and grants from Novartis, Ipsen, and Pfizer. F Beuschlein has received grant support from Novartis. $H$ Schneider has received lecture fees from Novartis and Pfizer and research grants from Pfizer. J Schopohl has received lecture fees from Novartis, Ipsen, and Pfizer. All the other authors declare that there is no conflict of interest that could be perceived as prejudicing the impartiality of the research reported.

\section{Funding}

This work is part of the German Cushing registry CUSTODES and was supported by a grant from the Else Kröner-Fresenius Stiftung (grant number 2012_A103 to M Reincke). Furthermore, this project was funded by the German Federal Ministry of Education and Research, Leading-Edge Cluster $\mathrm{m}^{4}$.

\section{Acknowledgements}

This study was only feasible thanks to the continuous and enthusiastic support of our clinical Cushing's team, especially Mrs Sabrina Hierse, who collected data and managed patient aftercare.

\section{References}

1 Newell-Price J, Trainer P, Besser M \& Grossman A. The diagnosis and differential diagnosis of Cushing's syndrome and pseudo-Cushing's states. Endocrine Reviews 199819 647-672. (doi:10.1210/edrv.19.5.0346)

2 Swearingen B, Katznelson L, Miller K, Grinspoon S, Waltman A, Dorer DJ, Klibanski A \& Biller BM. Diagnostic errors after inferior petrosal sinus sampling. Journal of Clinical Endocrinology and Metabolism 200489 3752-3763. (doi:10.1210/jc.2003-032249)

3 Schurmeyer TH, Schulte HM, Avgerinos PC, Tomai TP, Loriaux DL, Gold PW \& Chrousos GP. Pharmacology of ovine and human CRH. Hormone and Metabolic Research. Supplement 198716 24-30.

4 Nieman LK \& Loriaux DL. Corticotropin-releasing hormone: clinical applications. Annual Review of Medicine 198940 331-339. (doi:10.1146/ annurev.me.40.020189.001555) 
5 Kaye TB \& Crapo L. The Cushing syndrome: an update on diagnostic tests. Annals of Internal Medicine 1990112 434-444. (doi:10.7326/00034819-76-3-112-6-434)

6 Nieman LK. Diagnostic tests for Cushing's syndrome. Annals of New York Academy of Sciences 2002970 112-118. (doi:10.1111/j.1749-6632. 2002.tb04417.x)

7 Newell-Price J, Perry L, Medbak S, Monson J, Savage M, Besser M \& Grossman A. A combined test using desmopressin and corticotropinreleasing hormone in the differential diagnosis of Cushing's syndrome. Journal of Clinical Endocrinology and Metabolism 199782 176-181. (doi:10.1210/jcem.82.1.3674)

8 Arnaldi G, Tirabassi G, Papa R, Furlani G, Trementino L, Cardinaletti M, Faloia E \& Boscaro M. Human corticotropin releasing hormone test performance in the differential diagnosis between Cushing's disease and pseudo-Cushing state is enhanced by combined ACTH and cortisol analysis. European Journal of Endocrinology 2009160 891-898. (doi:10.1530/EJE-09-0125)

9 Nieman LK, Cutler GB Jr, Oldfield EH, Loriaux DL \& Chrousos GP. The ovine corticotropin-releasing hormone ( $\mathrm{CRH})$ stimulation test is superior to the human CRH stimulation test for the diagnosis of Cushing's disease. Journal of Clinical Endocrinology and Metabolism 1989 69 165-169. (doi:10.1210/jcem-69-1-165)

10 Nieman LK, Oldfield EH, Wesley R, Chrousos GP, Loriaux DL \& Cutler GB Jr. A simplified morning ovine corticotropin-releasing hormone stimulation test for the differential diagnosis of adrenocorticotropin-dependent Cushing's syndrome. Journal of Clinical Endocrinology and Metabolism 199377 1308-1312. (doi:10.1210/jcem. 77.5.8077325)

11 Invitti C, Pecori Giraldi F, de Martin M \& Cavagnini F. Diagnosis and management of Cushing's syndrome: results of an Italian multicentre study. Study Group of the Italian Society of Endocrinology on the Pathophysiology of the Hypothalamic-Pituitary-Adrenal Axis. Journal of Clinical Endocrinology and Metabolism 199984 440-448. (doi:10.1210/jcem.84.2.5465)

12 Dorin RI, Ferries LM, Roberts B, Qualls CR, Veldhuis JD \& Lisansky EJ. Assessment of stimulated and spontaneous adrenocorticotropin secretory dynamics identifies distinct components of cortisol feedback inhibition in healthy humans. Journal of Clinical Endocrinology and Metabolism 199681 3883-3891. (doi:10.1210/jcem.81.11.8923833)

13 Aron DC, Raff H \& Findling JW. Effectiveness versus efficacy: the limited value in clinical practice of high dose dexamethasone suppression testing in the differential diagnosis of adrenocorticotropin-dependent Cushing's syndrome. Journal of Clinical Endocrinology and Metabolism 199782 1780-1785. (doi:10.1210/jcem.82.6.3991)

14 Doi M, Sugiyama T, Izumiyama H, Yoshimoto T \& Hirata Y. Clinical features and management of ectopic ACTH syndrome at a single institute in Japan. Endocrinology Journal 201057 1061-1069. (doi:10.1507/endocri.K10E-265)

15 Ilias I \& Mastorakos G. The emerging role of peripheral corticotropinreleasing hormone (CRH). Journal of Endocrinological Investigation 2003 26 364-371. (doi:10.1007/BF03345186)

16 Isidori AM, Kaltsas GA, Mohammed S, Morris DG, Jenkins P, Chew SL, Monson JP, Besser GM \& Grossman AB. Discriminatory value of the low-dose dexamethasone suppression test in establishing the diagnosis and differential diagnosis of Cushing's syndrome. Journal of Clinical Endocrinology and Metabolism 200388 5299-5306. (doi:10.1210/jc. 2003-030510)

17 Isidori AM, Kaltsas GA, Pozza C, Frajese V, Newell-Price J, Reznek RH, Jenkins PJ, Monson JP, Grossman AB \& Besser GM. The ectopic adrenocorticotropin syndrome: clinical features, diagnosis, management, and long-term follow-up. Journal of Clinical Endocrinology and Metabolism 200691 371-377. (doi:10.1210/jc.2005-1542)

18 Malchoff CD, Orth DN, Abboud C, Carney JA, Pairolero PC, Carey RM \& Ectopic ACTH. syndrome caused by a bronchial carcinoid tumor responsive to dexamethasone, metyrapone, and corticotropinreleasing factor. American Journal of Medicine 198884 760-764. (doi:10.1016/0002-9343(88)90116-7)

19 Suda T, Kageyama K, Nigawara T \& Sakihara S. Evaluation of diagnostic tests for ACTH-dependent Cushing's syndrome. Endocrinology Journal 200956 469-476. (doi:10.1507/endocrj.K08E-353)

20 Arnaldi G, Angeli A, Atkinson AB, Bertagna X, Cavagnini F, Chrousos GP, Fava GA, Findling JW, Gaillard RC, Grossman AB et al. Diagnosis and complications of Cushing's syndrome: a consensus statement. Journal of Clinical Endocrinology and Metabolism $2003 \mathbf{8 8}$ 5593-5602. (doi:10.1210/jc.2003-030871)

21 Newell-Price J, Morris DG, Drake WM, Korbonits M, Monson JP, Besser GM \& Grossman AB. Optimal response criteria for the human $\mathrm{CRH}$ test in the differential diagnosis of ACTH-dependent Cushing's syndrome. Journal of Clinical Endocrinology and Metabolism 200287 1640-1645. (doi:10.1210/jcem.87.4.8357)

22 Reimondo G, Paccotti P, Minetto M, Termine A, Stura G, Bergui M, Angeli A \& Terzolo M. The corticotrophin-releasing hormone test is the most reliable noninvasive method to differentiate pituitary from ectopic ACTH secretion in Cushing's syndrome. Clinical Endocrinology 200358 718-724. (doi:10.1046/j.1365-2265.2003.01776.x)

23 Ilias I, Torpy DJ, Pacak K, Mullen N, Wesley RA \& Nieman LK. Cushing's syndrome due to ectopic corticotropin secretion: twenty years' experience at the National Institutes of Health. Journal of Clinical Endocrinology and Metabolism 200590 4955-4962. (doi:10.1210/ jc.2004-2527)

24 Newell-Price J, Bertagna X, Grossman AB \& Nieman LK. Cushing's syndrome. Lancet 2006367 1605-1617. (doi:10.1016/S01406736(06)68699-6)

25 Colao A, Faggiano A, Pivonello R, Pecori Giraldi F, Cavagnini F \& Lombardi G. Inferior petrosal sinus sampling in the differential diagnosis of Cushing's syndrome: results of an Italian multicenter study. European Journal of Endocrinology 2001144 499-507. (doi:10.1530/eje.0.1440499)

26 Doppman JL, Chang R, Oldfield EH, Chrousos G, Stratakis CA \& Nieman LK. The hypoplastic inferior petrosal sinus: a potential source of false-negative results in petrosal sampling for Cushing's disease. Journal of Clinical Endocrinology and Metabolism 199984 533-540. (doi:10.1210/jcem.84.2.5475)

27 Sharma ST \& Nieman LK. Is prolactin measurement of value during inferior petrosal sinus sampling in patients with adrenocorticotropic hormone-dependent Cushing's Syndrome? Journal of Endocrinological Investigation 201336 1112-1116. (doi:10.3275/9067)
Received 23 October 2014

Revised version received 9 April 2015

Accepted 6 May 2015 